\title{
Explaining the Global Digital Divide: Economic, Political and Sociological Drivers of Cross- National Internet Use
}

\author{
Mauro F. Guillén, University of Pennsylvania \\ Sandra L. Suárez, Temple University
}

\begin{abstract}
We argue that the global digital divide, as measured by cross-national differences in Internet use, is the result of the economic, regulatory and sociopolitical characteristics of countries and their evolution over time. We predict Internet use to increase with worldsystem status, privatization and competition in the telecommunications sector, democracy and cosmopolitanism. Using data on 118 countries from 1997 through 2001, we find relatively robust support for each of our hypotheses. We conclude by exploring the implications of this new, powerful communication medium for the global political economy and for the spread of democracy around the world.
\end{abstract}

The Internet has developed unevenly throughout the world, creating what has become known as the "global digital divide" (Castells 2001; Kirkman et al. 2002; Mosaic Group 1998; Norris 2001; Rogers 2001). The number of Internet users is one of the most widely used indicators of development of this emerging medium of communication. Less than 10 percent of the world's population uses the Internet, and the gap between developed and developing countries has continued to widen since the early 1990s (see Figure 1). Differences by country are remarkable. Statistics compiled by the International Telecommunication Union as of the end of 2002 indicate that Internet use as a proportion of the population ranges from less than one percent in many underdeveloped African, Central American, and South Asian countries to between 50 and 60 percent in Iceland, the United States, Scandinavia, Singapore or South Korea (ITU 2003). ${ }^{1}$

The growth of the Internet has captured the imagination of users, policymakers, entrepreneurs, corporate managers, military strategists, social commentators, scholars, and journalists. Some early optimistic analyses envisioned the Internet as a "decentralizing, globalizing, harmonizing, and empowering" medium (Negroponte 1995:229), as a new communication technology that would bring about a "smaller, more open world." (Tapscott and Caston 1993:313) The most enthusiastic visionaries have argued that the Internet means the "triumph over time and space," the rise of the "netizen," and the crowning of the "customer as sovereign" (Gilder 2000). According to the cyber-optimists, the Internet can create a public sphere in Habermas's (1989) sense, one that is not regulated by the state or by commercial interests but rather owned and controlled by the participants themselves (Schneider 1996).

While some of the cyber-optimists recognized the looming issue of inequality in access to the Internet (e.g. Tapscott and Caston 1993:312), it was not until the late 1990s that international organizations, governments, think tanks, and universities started to warn about the existence of a yawning digital divide, both within and across countries (e.g., U.S.

Direct correspondences to Mauro F. Guillen, The Wharton School, University of Pennsylvania, 2000 Steinberg Hall-Dietrich Hall, 3620 Locust Walk, Philadelphia, PA 19104-6370. Email: guillen@wharton.upenn.edu. 
Department of Commerce 1999; UCLA 2000; Horrigan 2003; for a review, see Norris 2001). Though revolutionary in many respects, the Internet has not yet brought about the economic, political, and social improvements predicted by some (for reviews, see: DiMaggio et al. 2001; Norris 2001; Putnam 2001:169-180; Wellman 2001; Wynn and Katz 1997).

The key theoretical problem with the optimistic prospects lies in the assumption that new technology enables everyone. Scholars have noted that the Internet tends to reinforce existing class and social relations both within and across countries (Mosco 1996; McChesney 1999; Everett 1998). Critical mass communication scholars point out that a "handful of private, giant, communications conglomerates" enabled by governments dominate the media industry, disenfranchising rather than enabling people. These authors argue that the media conglomerates view the Internet as an "online shopping mall" rather than as a public sphere á la Habermas (1989), and predict that, unless the development of the Internet changes course and becomes driven by the needs of citizens, its current path will likely exacerbate social inequalities (McChesney 1999, 2000; Mosco 2000; see also: Wasko 2001; Jones 2000; Herman and Chomsky 1988). Most researchers agree that the Internet has both empowered and discriminated, enabling some to pursue a better life while leaving the majority of the world's population behind. As Castells (2001:247) concludes, "the heralding of the Internet's potential as a means of freedom, productivity, and communication comes hand in hand with the denunciation of the 'digital divide' induced by inequality on the Internet."

\section{Figure 1: Internet Users Worldwide, 1990-2001}

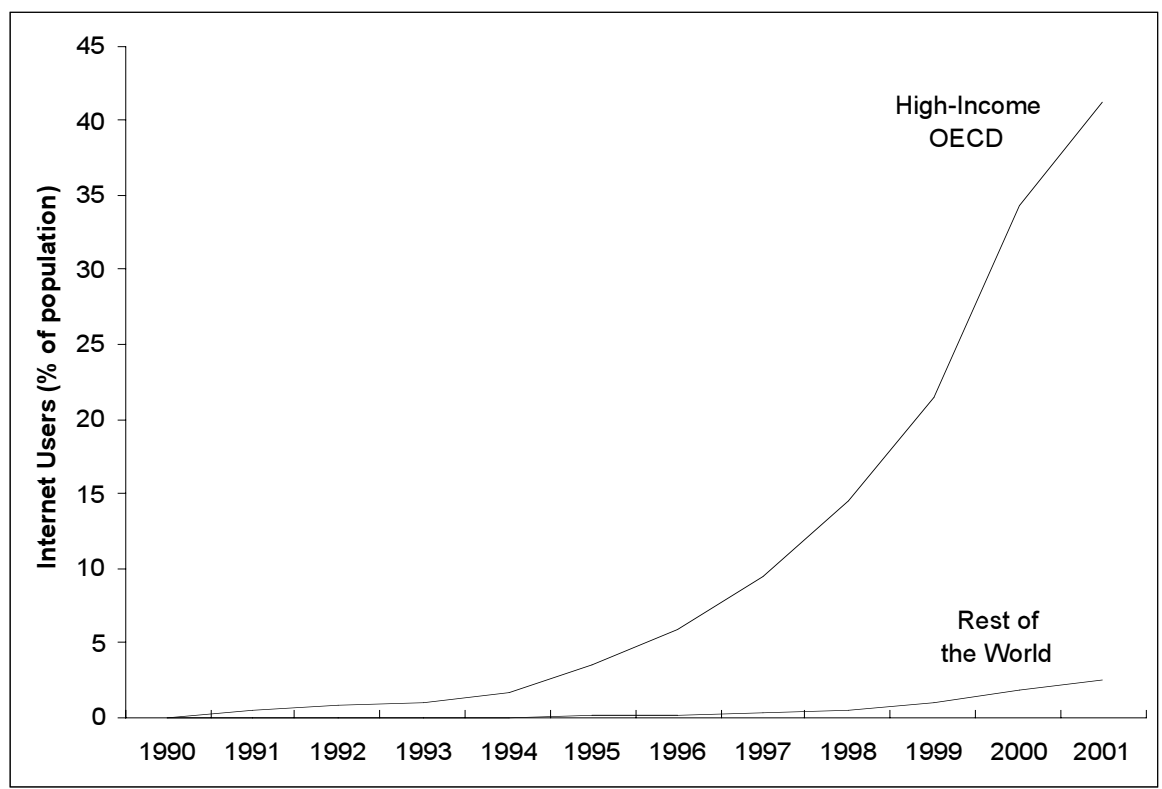

Source: World Bank (2003). Note: There are 24 countries classified as High-Income OECD.

In spite of the growing acceptance of the existence of a global digital divide, there is no agreement in the literature as to its causes. Much previous research has found that differences in Internet use across countries are fundamentally related to economic variables such as per capita income and the cost of access. The nature of the data used differs from study to study, the norm being aggregate data at the country level. ${ }^{2}$ Some researchers have 
analyzed cross-sectional data for the most advanced countries only (Hargittai 1999; Oxley and Yeung 2001), while others have examined data at one point in time but including developing as well as developed countries (Beilock and Dimitrova 2003; Guillén and Suárez 2001; Maitland and Bauer 2001; Norris 2001:58-64; Volken 2002). A third group of previous studies has used pooled cross-section time-series data for the most advanced countries (Bauer, Berne and Maitland 2002), finding that, in addition to income and cost, competition in telecommunication services also increases Internet use. Only one published study (of Internet computer hosts) has analyzed longitudinal data for both developed and developing countries (Kiiski and Pohjola 2002). They also found per capita income and cost of access to be significant determinants of differences across countries. An excellent forthcoming paper uses pooled data, finding that economic, political and emulation variables increase Internet use and hosting (Milner 2006). Another unpublished study used cross-sectional panel data for both developing and developed countries (Chinn and Fairlie 2004), and also found a strong effect of per capita income. Based on the findings reported in the literature and on her own crosssectional analysis at the country level, Norris (2001:63) observed that political and social explanations of the global digital divide do not seem to hold once income and cost of access are controlled for, and concludes that "economic factors outweighed all others in predicting cross-national differences in access to the information society."

In this paper we propose to analyze Internet use around the world by taking into account not only economic variables but also regulatory, political and sociological ones. Thus, we extend and improve previous research by systematically assessing the impact of worldsystem status, telecommunications policymaking, political regimes, and social relationships. Unlike previous research, we find that regulatory, political and sociological variables are also responsible for the global digital divide.

\section{The Drivers of the Global Spread of the Internet}

Our approach to the study of the global digital divide is based on the well-established argument and finding that the diffusion of innovations in general, and of communication media in particular, follows complex patterns shaped not only by the technical merits of the innovation itself but also by the economic, political, and sociological context in which it occurs. (For a review, see Rogers 1995.) Our theoretical and empirical analysis of the global digital divide controls for the effects of three variables commonly found to affect access and use of new media, namely, socioeconomic status, the existence of an enabling infrastructure, and the cost of access. Let us analyze each of them before we turn to the regulatory, political, and sociological variables that are the focus of the paper.

\section{Socioeconomic Status, Accessibility and Cost}

By far the most frequently replicated finding in the literature is that communication media are more likely to be adopted or used the higher the socioeconomic status. A long tradition of research in media studies confirms the so-called "knowledge gap" hypothesis (Star and Hughes 1950; Tichenor, Donohue and Olien 1970), whereby people differ in the extent to which they use means of mass communication to acquire information. Those of a higher socioeconomic status use them at a higher rate, and the gap between the segments increases over time (Viswanath and Finnegan 1996). As noted above, a variety of empirical studies of the global digital divide using aggregate data have found evidence to the effect that the average standard of living and the average educational level in a country - arguably the 
analogs of socioeconomic status at the individual level - are strong predictors of Internet use (e.g. Hargittai 1999; Guillén and Suárez 2001; Maitland and Bauer 2001; Chinn and Fairlie 2004; Norris 2001:58-64). Using individual-level data gathered in 24 countries, Chen, Boase and Wellman (2002) also found a strong correlation between socioeconomic status and Internet use.

Countless studies of media diffusion have also established that use is facilitated by the existence of an enabling infrastructure (e.g. phone lines in the case of telephone use) and sufficiently low cost of access. The case of the telephone is perhaps the most thoroughly researched (see, for instance, Fischer 1992). Numerous are also the empirical studies that find the availability of an enabling infrastructure and affordable cost of access to spur Internet use. Some of these studies use aggregate cross-national data (Guillén and Suárez 2001; Kiiski and Pohjola 2002; Chinn and Fairlie 2004; Milner 2006), though the majority analyze detailed, individual-level information (e.g. U.S. Department of Commerce 1999; UCLA 2000, 2003; Chen, Boase and Wellman 2002).

Our theoretical contribution to the study of the global digital divide is to conceptualize the impact of regulatory, political, and sociological variables in addition to income, accessibility, and cost. We focus the attention on dependency, policymaking in the telecommunications sector and market, democracy, and social relationships as drivers of Internet use.

\section{Dependency and World-System Status}

The development of countries along a certain dimension like income per capita or Internet use, however, is not a linear process from less developed to more. Dependency theory and world-system analysis have contributed a body of theoretical and empirical literature showing that developing countries are dependent on more advanced ones for capital, technology and access to information. Such a dependent relationship perpetuates patterns of inequality at the global level. Dependency theorists observe that the terms of trade between advanced (core) countries and developing (peripheral) countries tend to evolve to the detriment of the latter. As a result, peripheral countries become relatively more impoverished (Pritchett 1997). Likewise, world-system scholars see underdevelopment as the result of a country's integration into the modern "world-system" created by the capitalist development of Western Europe and its more successful offshoot colonies, e.g. the United States, Canada or Australia. In their view, global capitalist forces generate profound inequalities between the developed "core," the developing "semi-periphery," and the undeveloped "periphery" (Wallerstein 1974; Ragin and Chirot 1984; Smith and White 1992; Van Rossem 1996). The key point in dependency and world-system research is that tighter integration with the rest of the world does not necessarily lead to greater economic growth or social well-being. It depends on whether the country is part of the core or the periphery, that is, on the nature of the relationship.

Communication scholars attuned to dependency theory have long pointed out that the development of the media and the digital revolution are driven by political-economic forces, including the activities of media corporations and the policies of the dominant states in the world (Davidson 2002; McChesney 1999; Mosco 1996; Schiller 1996). The Internet is presented as a medium that offers not only opportunities but also threatens to exacerbate technology gaps. Research has shown that the geographical distribution of high-technology exports, computer power, and Internet hosts follows the hierarchical pattern of the coreperiphery system, although there is no single core but a triadic arrangement of country clusters around the cores of Western Europe, North East Asia and the United States, each with their respective peripheries (Gunaratne 2002). There is also micro-level evidence 
indicating that the use of Internet tools in development programs organized by international aid agencies tends to produce dependency and uneven growth. In a review of evidence from Latin America, Everett (1998:386) found that "information does not always ensure progress, and integration does not ensure equality. [...] Information technology is leading to new forms of dependency," especially in the urban slums and the rural areas where the vast majority of the population of the developing world lives.

If world-system position - periphery, semi-periphery or core - shapes a country's development possibilities, it is reasonable to predict that Internet use will grow more quickly in countries that enjoy a more favorable position in the international system of states. Therefore, we formulate:

Hypothesis 1: World-system status increases Internet use.

\section{Policymaking in Telecommunications}

Notwithstanding dependency and world-system position, countries may affect the rate at which new media are adopted by engaging in policymaking and regulation. The Internet is part of the institutionally complex, economically important, tightly regulated, and highly politicized telecommunications sector (D'Souza and Megginson 1999b). National telecommunications systems and markets differ in their reach, quality and cost, which in turn are affected by the ways in which regulation takes place, the ownership of companies active in the sector, and the intensity of competition. It is important to note that competition can translate not only into lower prices (or costs of access and use to the user) but also in more service differentiation, choice, and quality. Thus, policymaking in this area tends to have a large impact on the various dimensions of media access and use. For instance, in his study of the early diffusion of the telephone in the United States, Fischer (1992:86-121) found that use was not only affected by family income but also by competition among companies, which translated into renewed marketing efforts, higher quality, and, of course, lower prices.

Until 1980 growth rates and prices in telecommunications markets around the world remained relatively stable. Except in the case of the most highly developed countries, most people did not use telecommunication services frequently. Basically, people could only afford telephone services, for example, when their incomes grew as a result of industrialization. During the 1980s and 1990s privatization - or the partial or total sale of previously state-owned telecommunications operators - and competitive deregulation have changed this relatively stagnant situation in many parts of the world. As a result, the use of telecommunications services has expanded rapidly. Previous research has established that deregulation, privatization and competition tend to enhance the operating and financial performance of public utilities in general (D'Souza and Megginson 1999a; Megginson and Netter 2001), although adoption of such policies is very uneven (Henisz, Zelner and Guillén 2005). The evidence on the telecommunications sector during the 1980s and 1990s demonstrates the positive effects of the new policies. In a study of 26 privatized telecommunications firms in 21 countries, D'Souza and Megginson (1999b) found that profitability, output, efficiency, capital expenditure, lines in service, and average salary per employee all increased after privatization. (Net employment remained roughly the same.) Furthermore, the reasons for such increases were not higher prices but efficiency gains, which were further enhanced if competition and deregulation accompanied privatization (see also: Levy and Spiller 1994; Gutiérrez and Berg 2000). Using data on 30 countries in Africa and Latin America, Wallsten (2001) also found that privatization improved the performance of the telecommunications sector especially when combined with the separation of the regulatory authority from the incumbent 
telecommunications company. Petrazzini and Clark (1996) found that deregulation was more beneficial than privatization in a sample of 26 developing countries.

Privatization, however, has not been adopted by all countries. As of the end of 1994, only 50 out of a total 206 countries and territories in the world had privatized at least in part the incumbent telecommunications operator, and just 23 had privatized it in full. By the end of 1999 the numbers had almost doubled to 80 and 74, respectively (ITU 2000, 2003). Similarly, at the end of 1994 only 15 countries had introduced competition in local telephone service, compared to 47 five years later.

These differences in the adoption of policies of privatization and competition in telecommunications affect the availability, affordability, and quality of Internet use because most people continue to access the Internet using a dialup connection (ITU 2003). In the United States, for instance, one of the most Internet-ready societies, only 7 percent of users as of the end of 2000 accessed the Internet with a cable or digital subscriber line (DSL) broadband service. The only two other countries with a higher use of broadband than the U.S. at that time were Canada (14 percent) and South Korea (28 percent). The proportion for most countries was less than 2 percent (Kirkman et al. 2002:151). As of March 2003, 31 percent of U.S. home Internet users had a high-speed connection (Horrigan 2003:1).

The importance of privatization and competition to the growth of the Internet has been highlighted in a large number of reports and analyses (Kirkman et al. 2002:118-158). The expansion of telecommunication markets through privatization, deregulation, and enhanced competition has frequently been proposed as key to the transition to the global information society (Wilson 1998). Cross-national studies using time-series data on the most advanced countries have found support for the effect of competition on Internet use, controlling for cost of access (Bauer et al. 2002). Thus, previous theoretical and empirical work on telecommunications in general and the Internet in particular suggests that policies such as privatization and enhanced competition foster the development of the media thanks to an expansion in the scope of the market in terms of service differentiation, choice and quality, even controlling for price. Therefore, we formulate:

Hypothesis 2: The privatization of the incumbent telecommunications provider increases Internet use.

Hypothesis 3: Competition in local phone service increases Internet use.

\section{Democracy and the Internet}

The development of mass communication media such as the postal system, the newspaper, the telephone, television, and now the Internet has occurred not just in an economic or regulatory context but also in a political one. We contend that during the early stages of the worldwide diffusion of this new medium, at a time when still less than ten percent of the world's population uses the web, the political regime prevalent in a given society is an exogenous influence on Internet development because it is a variable historically and causally prior to the emergence of the Internet as a popular means of communication during the late 1990s (Norris 2001:58-64; van Dijk 1999). As Bobrow (1973-1974:561) has pointed out, politicians and political regimes can shape various aspects of the process of mass communication, including "message content, media personnel and technology, cultural level of messages, and availability of the media output" (see also O'Sullivan et al. 1983). ${ }^{3}$

Our analysis of the impact of political regime on Internet use starts by observing that the media differ according to the kind of mass communication that they enable, as posited by 
communication scholars (Lorimer 2002). First, centralized mass communication entails information or entertainment dissemination to large audiences in ways that make it relatively easy for the sender to monitor and/or suppress information. Media as diverse as radio, television, newspapers, magazines, film, books, recorded music and advertising tend to enable this type of communication, although recent technological advances have reduced the censoring ability of the sender. Second, decentralized mass communication of information and entertainment is only possible with media like the telephone, e-mail or the web because they enable the user to take the initiative and choose what information to receive. And third, public mass communication is the exchange that takes place between individuals or groups at their own initiative through "publicly accessible, sometimes state-regulated channels" like the telephone, the mail system, pagers, two-way radio and e-mail, chatrooms, and other Internet-enabled means (Lorimer 2002:69).

Our argument is that democratic political regimes enable a faster growth of the Internet than authoritarian or totalitarian regimes, controlling for economic development and income. Media that enable either decentralized mass communication (i.e. the user exercises discretion over access to information) or public mass communication (i.e. exchanges between individuals and groups are possible) undermine the effectiveness of authoritarian or totalitarian rule by allowing citizens to secure their own information (as opposed to that sponsored by the regime), and to communicate with one another and potentially mobilize politically (Bobrow 1973-1974; Norris 2001:60-61, 100-101). These two types of media pose a threat to the monopoly over information production, storage, dissemination, and communication that authoritarian and totalitarian regimes seek to establish and maintain. In democratic countries, although media conglomerates have come to shape the information available on the Internet (McChesney 1999, 2000; Mosco and Foster 2001; Schiller 1996), users still have much more autonomy than in authoritarian or totalitarian ones to establish unhindered communication and be a source of information for each other.

Previous sociological research has demonstrated that dictatorships prefer communication media that enable centralized mass communication, while democracies tend to promote media in which the user has discretion either to access information or to engage in exchange with other individuals or groups. For example, Buchner (1988) found that in democratic countries use of the telephone diffused more rapidly and to a greater extent than use of television; his theoretical argument being that the telephone allows for more user autonomy and discretion, while television is a centralized medium easily controlled by the government, a comparison echoed by communication scholars (van Dijk 1999:31-33).

This argument has been extended by Havick (2000) to the case of the Internet. He argues that on the Internet, unlike television, "users may retrieve or communicate information 24 h[ours] a day," and that "Internet information is easily copied and sent to other people. Rather than being transitory, Internet information is difficult to stop, retract or erase because it is likely to be stored in countless computers." (Havick 2000:278) Norris (2001:60-61, 100-101) argues that the greater civil liberties of democracy would be consistent with greater access to and use of the Internet, and that governments find it more difficult to censor free expression on the Internet than on television. ${ }^{4}$ Rogers (2001:98) concurs in that "the decentralized nature of the Internet means that its message content is very difficult or impossible for governments, parents, or other gatekeepers to control." And communication scholars have explicitly argued that in an age of electronic communication totalitarian or authoritarian regimes find it harder to control information, communication, dissidents, and the press (O'Sullivan et al. 1983; Sussman 2000; van Dijk 1999:82-85; for the dissenting view, see Samoriski 2000).

There is ample case study evidence indicating that, in attempting to secure their stability and survival, authoritarian and totalitarian regimes regulate the use of the Internet in a variety of ways that are detrimental to use. Governmental efforts to control the Internet may include: 
(1) restricting access by controlling networks and instituting registration requirements; (2) restricting content by the filtering of information, blocking of forbidden sites, disciplinary actions, and even virus attacks on banned sites; and (3) credibly threatening to arrest or imprison those who access unauthorized information or use the Internet to organize and mobilize politically.

In the most extreme case, the authoritarian or totalitarian government directly controls all of the physical access to the Internet. For instance, North Korea does not allow any access to the Internet (Radio Free Europe 1999). In Cuba, public Internet access is restricted to a selected number of universities and employers. There is no opportunity to access the Internet individually or outside of the workplace (Boas 2000; Drake, Kelathil and Boas 2000). Similarly, in Myanmar all computer owners have to have a license, there is no public access to the Internet, and account owners are not permitted to share them (Leduc 2000). China has reportedly been trying to restrict access to material it considers undesirable by preventing the spread of the Internet, allegedly preferring access through cybercafés over use in private spaces (Holloway 2002; Zittrain and Edelman 2003). This might explain why 99 percent of Chinese homes do not have a computer (Franda 2002:195). Even before the country was connected to the Internet, Hanoi issued restrictions that could result in the shutdown of service providers "to prevent sources of bad information from entering Vietnam." (Yamamoto 1996) Middle Eastern Arab leaders initially slowed the pace of Internet diffusion for fear that "loss of control over basic information networks might result in revolutionary political change." (Franda 2002:55) In May 2001, the Iranian government shut down about 400 cybercafés, with only a few having reopened by early 2003 (Iran 2003).

Totalitarian and authoritarian regimes can also attempt to control Internet use by monitoring access to specific websites or types of content. The use of proxy servers as a censoring tool to filter information and prevent access to specific forbidden sites tends to slow down the speed of information flow, thus discouraging use of the Internet and limiting its diffusion, as has been reported in Singapore and Saudi Arabia (Hancock 1999; Hogan 1999; Rodan 1996, 1998; AP 2001; Zittrain and Edelman 2002). Politically motivated shutdowns of websites, discussion groups, Internet service providers (ISPs) or cybercafés tend to be highly disruptive actions. For instance, in 2001 alone, China shut down 17,000 cybercafés because they did not install the software required to restrict access to officially banned websites, which some estimate to be as much as ten percent of the total number of sites. Sites with words like "Tibet," "democracy" and "freedom" are commonly blocked by the government (Holloway 2002).

A third way in which Internet use can be discouraged by authoritarian or totalitarian regimes involves the fear of arrest and imprisonment that may result from sending or receiving unauthorized information. In Vietnam, democracy advocates or cyber-dissidents have been arrested and received harsh sentences for their pro-democracy activities over the Internet. ${ }^{5}$ Similar developments have been reported in China (Abbott 2001; Cooper 2000; Taubman 1998).

It is important to note that Internet diffusion may be slowed down if politically motivated governmental restrictions drive foreign investment in telecommunications away from countries that lack domestic capital. This argument has been made in the case of China, where investors are warned of the difficulties of operating profitably in such a highly regulated environment in spite of the absolute high number of users (Sohmen 2001). Fear of scaring foreign investors away led the government of Malaysia to end restrictions, including monitoring Internet activity for messages considered a threat to national security and requiring cybercafés to register with the government (McDaniel 2002:170-172; Legard 1999).

Given the decentralized and user-initiated nature of the communication that the Internet enables, the challenges and threats that this entails to political regimes in which democratic 
freedoms are not protected, and, accordingly, the access restrictions and the threats that such regimes impose on the population, we formulate:

Hypothesis 4: The more democratic the polity, the greater the Internet use. ${ }^{6}$

\section{Social Relationships and the Internet}

Just as prevailing political conditions exert an effect on the growth of communication media, different types of social behaviors and relationships also have the potential of shaping media consumption. We begin our analysis by observing that people exhibit different patterns of relationships to others in terms of the size of their social circle, the strength of their ties, the average geographical distance over which they maintain relationships, and their propensity to enter into new relationships (Granovetter 1973). Given the characteristics of the Internet as a decentralized medium that enables user-initiated information retrieval and communication over longer distances at lower cost than, say, the telephone, and faster than the mail, we expect more Internet use among people with a wider social circle, a greater proportion of weak ties, longer-distance relationships, and a higher propensity to explore new contacts beyond their existing ones.?

We base our argument on Merton's (1968) classic distinction between two ideal-types of individuals in terms of their social behavior, namely, cosmopolitan and local patterns of interpersonal influence and communications behavior, an argument that he originally developed in the 1950s as the theoretical framework to underpin an empirical study of the readership of Time magazine. According to Merton's ideal-typical conceptualization, locals have many friends and relationships in their own town, have lived there for a long time, do not travel frequently, and consume less media content than cosmopolitans. Cosmopolitans, by contrast, have more diverse social contacts, travel more frequently and widely, move their residence more often, and consume more media content, especially about foreign and domestic affairs, and the arts. The "culture of cosmopolitanism" is commonly defined by sociologists as including elements such as geographical mobility, frequent travel, and a curiosity about other places and cultures (Szerszynski and Urry 2002:470; Beck 2000). The mass communication literature confirms that there is a connection between cosmopolitanism and increased media use (for a review see Szerszynski and Urry 2002; see also Scannell 1996).

The evidence at the micro level is largely consistent with the link between cosmopolitanism and Internet use. A variety of studies in the United States, Canada, Europe, and worldwide using methods ranging from ethnography to panel surveys stretching over several years, and focusing on representative samples of the entire population or on specific cities or towns - have found that, controlling for sociodemographic characteristics, both recent and long-term Internet users are more likely than non-users to have a geographically dispersed social circle, have relatively more weak ties to others, have lived for fewer years in their current house, and be frequently away from home for travel (Katz et al. 2001:413-414; Kraut et al. 1998:1029; Cummings, Butler and Kraut 2002:108; Chen, Boase and Wellman 2002:95). These characteristics map strikingly well on several dimensions of Merton's cosmopolitan ideal-type.

Similar results, consistent with the cosmopolitanism logic, were found at the wired Toronto suburb of Netville, with users being able to maintain and expand their long-distance relationships to a much greater extent than non-users. The impact of online experience was greater as the geographical distance with contacts increased (Hampton and Wellman 2002:359-365). In other surveys, respondents reported using email more often for longdistance relationships because of the obvious cost and time-zone considerations, although 
email is also heavily used for short-distance relations (Wellman et al. 2001:444; Boneva and Kraut 2002:391-392; Quan-Haase and Wellman 2002:302-303). Other surveys found that the sizes of both the local and the distant social circle increased as a result of sustained Internet use (Kraut et al. 2001:61; Robinson and Neustadtl 2002). Thus, while the micro-level evidence does not indicate that Internet users are more alienated or isolated than non-users, it shows that users can establish and maintain longer-distance relationships more easily, and hence become more cosmopolitan in their behavior than non-users.

The patterns of media consumption of the cosmopolitan ideal-type, as identified by Merton (1968), tend to be consistent with Internet use as well. Surveys representative of the U.S. and other countries show that Internet users consume slightly more books, newspapers, recorded music, and radio than comparable non-users, although the differences are small, and in some samples they disappear once socioeconomic characteristics are controlled for (e.g. Chen, Boase and Wellman 2002:91; Robinson et al. 2002:255).

Based on the micro-behavioral processes and evidence described above, we expect that Internet use in a given country will increase the more its people are engaged in cosmopolitan patterns of social relationships, including aspects such as having a larger social circle, a greater proportion of weaker ties to others, a greater average geographical distance over which relationships are maintained, and a higher propensity to enter into new relationships. Hence,

Hypothesis 5: The more cosmopolitan the society, the greater the Internet use.

\section{Data and Methods}

We have compiled a cross-national and longitudinal dataset on the economic, regulatory, political, and sociological determinants of Internet use in which the unit of analysis is the country-year. Our dependent variable is measured each year between 1997 and 2001, while our independent variables are measured with a one year lag. Missing data on one or more of the independent variables prevent us from extending the period under investigation beyond 2001. We measure Internet development with the number of Internet users per 100 population. Our source for the data is the International Telecommunication Union (ITU 2002:A89-A90; 2003). While there are alternative sources of data for Internet use (e.g. NUA 2003), the ITU data have several key advantages. Initially established in 1865, and a specialized agency of the United Nations since 1947, the ITU is the official compiler of international statistics on telecommunications. The ITU dataset covers more countries and territories than any other source (more than 200), and over a longer period of time. Moreover, the ITU sets standards for both telecommunications services and statistics, organizes meetings to harmonize data collection and reporting procedures, and offers data not just on the dependent variable considered in this paper but also on a number of the independent variables. The ITU is considered to be the best available source of information on the Internet around the world (Abramson 2000:70; Minges 2000). While the ITU has tracked Internet use since 1990, we start our analysis in 1997 because of the poor quality of the data prior to that year.

\section{Independent Variables}

We measure world-system status using Van Rossem's (1996) approach. Based on his analysis of imports, exports, arms trade, troop deployments and diplomatic ties, we use two dummy variables to designate the 15 countries in the "core" and 22 in the "semi-periphery," with 
peripheral countries as the omitted category. ${ }^{8}$ We measure telecommunications policies with two separate variables. First, we use a set of time-varying dummy variables to indicate whether the incumbent telephone company is fully privatized, majority privatized, minority privatized, or fully state-owned (omitted category). And second, we use a time-varying dummy variable to denote whether there is competition in local telephone service. These two variables were coded from information compiled by the ITU $(2000,2003)$ as well as from the websites of the national telecommunication regulatory authorities in each country. ${ }^{9}$

We measure democracy using the ten-point score included in the Polity IV database, which takes into account three elements: institutions to enable the people to express its political preferences, checks and balances on the executive's power, and "the guarantee of civil liberties to all citizens in their daily lives and in acts of political participation" (Marshall and Jaggers 2002:12). This indicator of democracy is especially well suited to study Internet use because it captures the extent to which citizens can express their preferences and civil liberties are protected. We approximate the degree of cosmopolitanism in the culture by the expenditure on tourism abroad by residents of the country, calculated as a percentage of GDP (World Bank 2003). This measure is a fair proxy for Merton's (1968) cosmopolitan ideal-type because it captures at an aggregate level the extent to which people travel, and are exposed to and part of wider networks of contacts. Beck (2000:97) and Szerszynski and Urry (2002:470) propose international travel as one of the key indicators of cosmopolitanism. Micro-level studies comparing Internet users to nonusers find that the former are more frequently away from home for travel (Katz et al. 2001:413-414; Kraut et al. 1998:1029; Cummings, Butler and Kraut 2002:108; Chen, Boase and Wellman 2002:95).

\section{Control Variables}

We include four control variables in all of our analyses: GDP per capita in constant 1995 dollars (World Bank 2003), as a measure of economic development and purchasing power; the number of telephone lines in operation per 100 population (ITU 2003), as a measure of the development of the telecommunications infrastructure; the cost of Internet access as measured by the price in U.S. dollars of a three-minute local call during peak hour (ITU 2003), as an indicator of the cost of Internet access given that in most countries the overwhelming majority of users have a dialup connection ${ }^{10}$ and a time trend. We report additional analyses controlling for education, for which the available empirical measures contain a large amount of missing data. The indicator that is available for the largest number of countries and years is literacy as a percentage of the adult population (World Bank 2004). Using this variable reduces our sample for analysis by 28 percent.

\section{Scaling and Magnitude of the Predicted Effects}

All independent variables are lagged one year. Both dependent and independent variables are logged so as to normalize their distribution, and to be able to interpret the magnitude of the point estimates in proportional terms. In addition, logging the dependent variable makes it possible to use regression models that assume a continuous, unbounded dependent variable. The number of users (which can be zero) and the democracy score (ranging between zero and 10) were rescaled by adding 1 in order to be able to calculate their logarithm. Following standard practice, dummy variables were not log transformed. The magnitude of the effect of a dummy variable is to be calculated by exponentiating the estimated regression coefficient and subtracting unity. 


\section{Estimation Methods}

Our data are repeated annual observations of the same fixed, i.e. not sampled, political units (countries). We estimate and report parameters and standard errors using several methods in order to test for robustness. The first is linear regression with panel-corrected standard errors (PCSEs). This method surmounts two estimation problems associated with pooled time-series cross-sectional data: panel heteroscedasticity and contemporaneous (i.e. cross-sectional) error correlation. To correct for the third common problem in cross-national time-series data, serial (i.e. longitudinal) error correlation, we add a lagged dependent variable (Beck 2001:290-291). The second method addresses the potential concern that our time series is relatively short (five years) by estimating the regression equations using heteroscedasticity-consistent standard errors (HCSEs; Long and Ervin 2000). We also add a lagged dependent variable to account for serial correlation. The HCSE method yields the same point estimates as PCSE, but different standard error estimates. The first two estimation methods surmount the three violations of the Gauss-Markov assumptions that occur when using panel data.

An alternative to adding the lagged dependent variable is to use country-fixed effects. This option seriously limits the ability of independent variables to explain variation because all crosssectional information is absorbed by the fixed effects. Using our data, only two variables would be consistently significant with fixed effects: GDP per capita and the number of telephone lines. As Beck (2001) notes, it is reasonable and justifiable under such circumstances to use a lagged dependent variable in order to correct for longitudinal error correlation, as long as one assesses the effectiveness of the lagged dependent variable at reducing the degree of serial correlation of errors with the appropriate Durbin's $h$ test (Durbin 1970). We calculate this test and find that the inclusion of a lagged dependent variable eliminates serial autocorrelation. ${ }^{11}$ Hence, using a lagged dependent variable instead of fixed effects is fully justified.

Finally, we report results with a generalized difference model as a further precaution and in order to make sure that our results are not spurious. This third method consists of estimating the regression equation using generalized least squares (GLS) with an $A R(1)$ disturbance (which accounts for a possible first-order autoregressive process) instead of the lagged dependent variable and the time trend, a method that also addresses the three violations of the GaussMarkov assumptions mentioned above.

We also conducted tests to ensure that the times-series data used in the analysis are trend stationary, thus further reducing the possibility that we obtain significant results based on spurious relationships. Hadri's (2000) LM tests confirmed that each time series used in the analysis was trend stationary, with the only exception of the number of telephone lines. It should be carefully noted that Hadri's LM tests require a perfectly balanced panel. Hence, we conducted them using the subsample of 305 country-years (61 countries and 5 years) for which there are no missing observations. We also ran the regressions using a method to correct for non-stationarity, i.e. the first difference model, as recommended by Beck (1991). The only significant variable was the number of telephone lines. ${ }^{12}$

\section{Results}

Table 1 reports the descriptive statistics and the correlation matrix using the sample of 118 countries with complete data on all variables (481 country-year observations). Table 2 shows the regression results, which provide support for several of our hypotheses when panel-corrected standard errors (PCSEs) are used to test for significance. Core and semi-peripheral countries have significantly more Internet users than peripheral countries $(\mathrm{H} 1)$. Privatization of the incumbent telecommunications operator fosters Internet use $(\mathrm{H} 2)$. One important note here is 


\begin{tabular}{|c|c|c|c|c|c|c|c|c|c|c|c|c|c|c|c|c|c|}
\hline$\stackrel{\square}{ }$ & & & & & & & & & & & & & & & & ¿ & \\
\hline$\stackrel{m}{=}$ & & & & & & & & & & & & & & & $\simeq$ & 8 & \\
\hline$\cong$ & & & & & & & & & & & & & & $\ddot{0}$ & \% & ஜூ &. \\
\hline$\mp$ & & & & & & & & & & & & ع & & 오․ & m్n. & 2 & \\
\hline 으 & & & & & & & & & & & প্ & $m$ & & $\hat{n}$ & $ㅇ$ & ष & \\
\hline o & & & & & & & & & & $\because$ & P & ल & & $m$ & 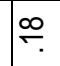 & ठ & 0 \\
\hline$\infty$ & & & & & & & & & నె & Ó. & 寸 & $g$ & & 5 & 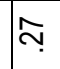 & 음. &.$\stackrel{0}{a} \frac{3}{a}$ \\
\hline 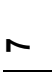 & & & & & & & & $\ddot{~}$ & 吉 & i. & N & $F$ & & ठ & 穵 & ஜ & 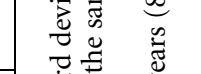 \\
\hline 0 & & & & & & & $\because$ & ১ & ర. & б. & 으. & $\hat{a}$ & & \% & $\stackrel{20}{\square}$ & 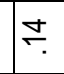 & 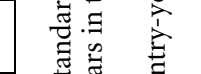 \\
\hline in & & & & & & $\stackrel{\Upsilon}{\Upsilon}$ & $\stackrel{+}{i}$ & ठ & & $\mp$ & $\mp$ & 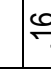 & & 8 & : & 8 & $\stackrel{\infty}{\vec{c}}$ \\
\hline$\nabla$ & & & & & 음 & \% & 오 & 10 & 요 & 8 & $\cong$ & 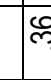 & & Oִ & $\mp$ & $\widetilde{\delta}$ & 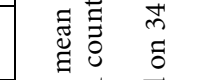 \\
\hline$m$ & & & & श & $\mp$ & $\mp$ & 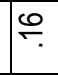 & in & @י & $\stackrel{\infty}{\circ}$ & $\stackrel{m}{R}$ & 1 & & m. & 오. & $\ddot{0}$ & 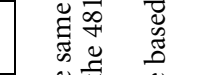 \\
\hline$\sim$ & & & ڤִ & 文 & $\rightleftarrows$ & $\cong$ & $\stackrel{2}{\sim}$ & 守 & م & गे. & $\infty$. & c & & छ़ & $\underset{\sim}{ }$ & m. & 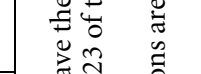 \\
\hline 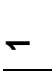 & & के. & 吕 & ஸ̣ & 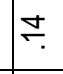 & $\cong$ & $\stackrel{2}{\sim}$ & 寸 & م & $\hat{m}$ & s. & : & & @ & 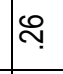 & ๓ొ. & Ẽ \\
\hline $\begin{array}{l}\text { वे } \\
\text { के } \\
\text { के }\end{array}$ & $\underset{\mathfrak{J}}{\mathfrak{N}}$ & i & 우․ & 夺 & 奶. & లి & "ొ & ษ. & ळo & $\stackrel{m}{r}$ & $\bar{\sigma}$ & ? & & $\stackrel{\infty}{\infty}$ & চு & 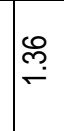 & 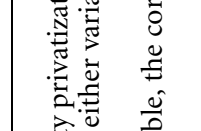 \\
\hline 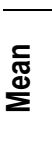 & 을 & $\frac{m}{6}$ & 유 & ஸ़ & 華 & 음 & ঙ্ & ஸ़ & প্ & $\frac{10}{10}$ & 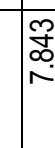 & $\underset{\approx}{\approx}$ & & 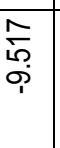 & 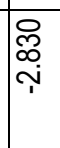 & \begin{tabular}{l}
$\infty$ \\
$\infty$ \\
$\infty$ \\
$\infty$ \\
\hdashline \\
\end{tabular} & 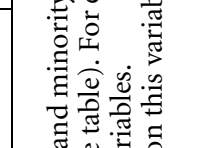 \\
\hline$\frac{\frac{0}{0}}{\frac{0}{\frac{\pi}{2}}}$ & 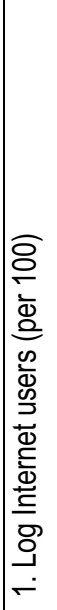 & 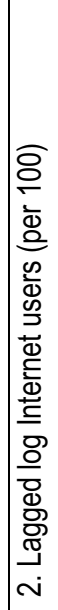 & 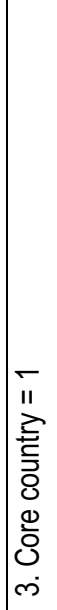 & 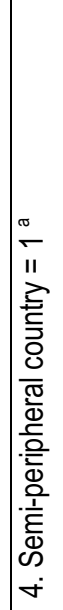 & 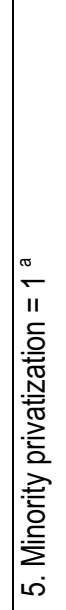 & 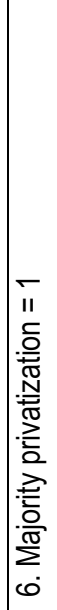 & 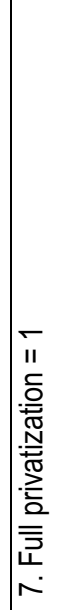 & 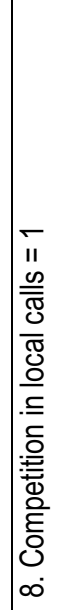 & 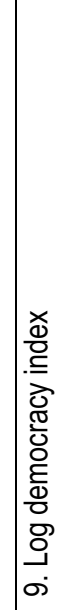 & 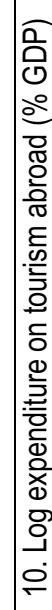 & 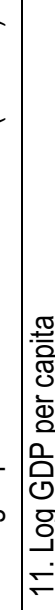 & 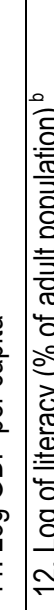 & 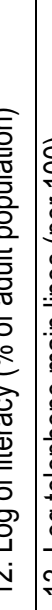 & 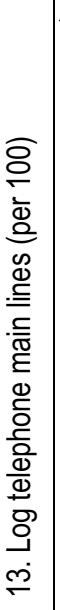 & 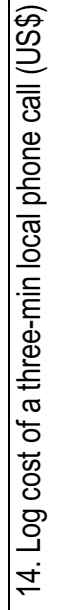 & 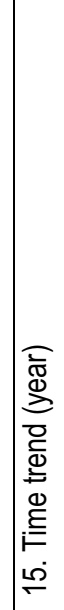 & 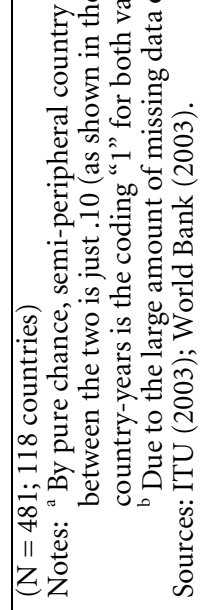 \\
\hline
\end{tabular}




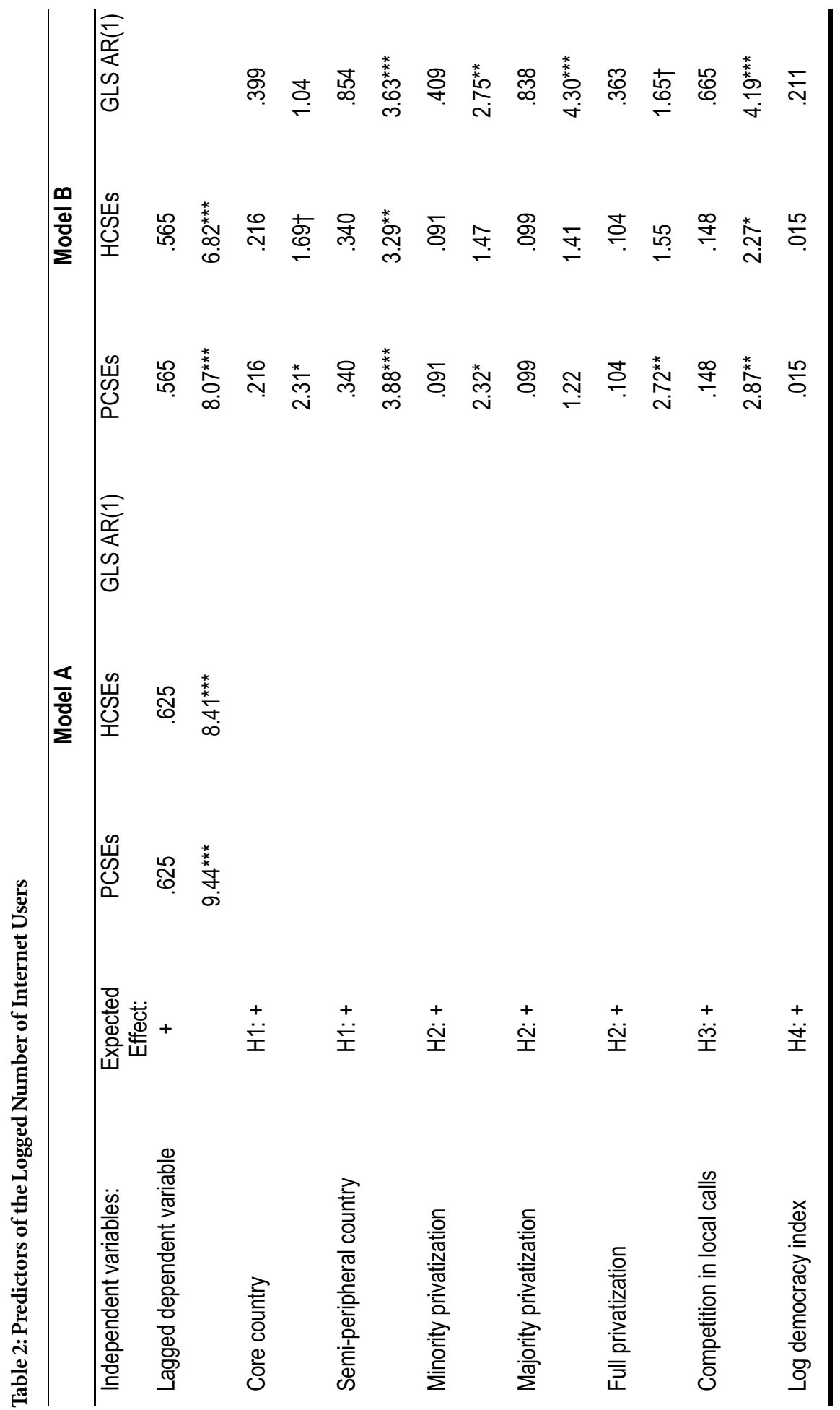




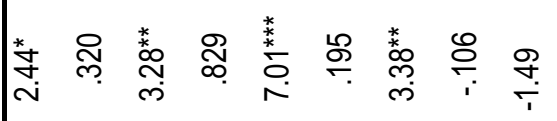

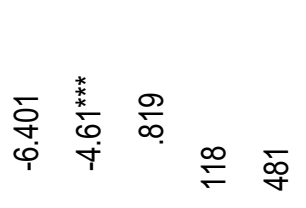

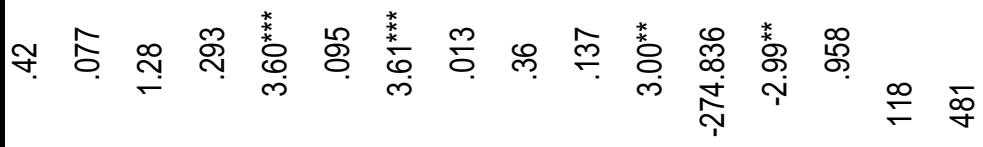

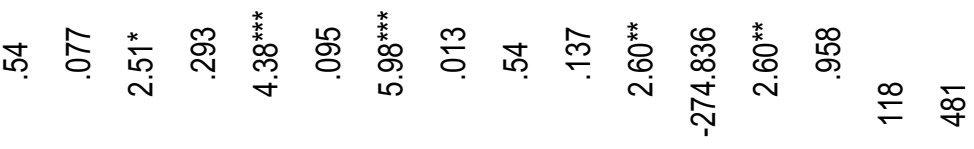

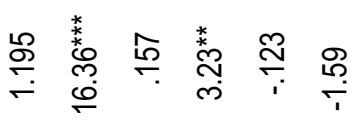

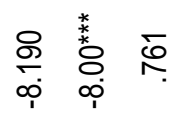

$\stackrel{\infty}{=}$

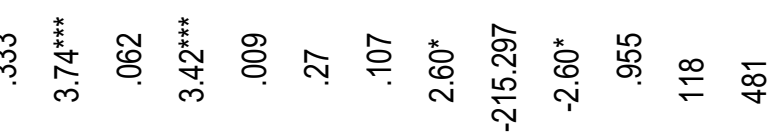

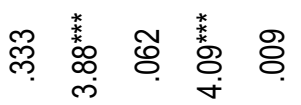

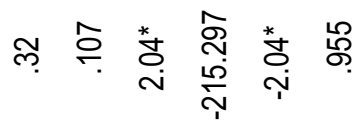

$\stackrel{\infty}{\rightleftharpoons}$

+்

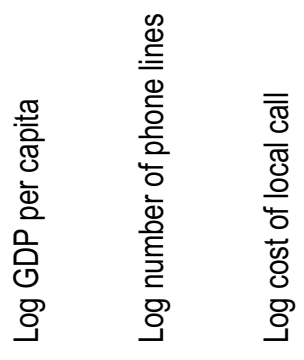

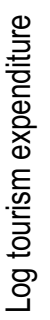

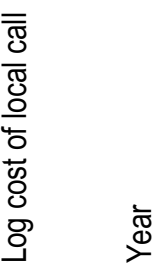

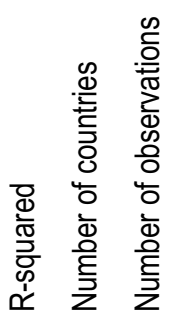


that the majority privatization dummy (when the state keeps less than 50 percent ownership) does not exert a significant effect, but minority (more than 50 percent) and full privatization (no state ownership) do. Recoding of the privatization dummies using different thresholds does not change the pattern of results. Competition in local telephone service also increases Internet use $(\mathrm{H} 3)$. Turning to political and sociological variables, democracy fails to reach significance $(\mathrm{H} 4)$, but cosmopolitanism does (H5). Two of the control variables (GDP per capita and the number of phone lines in operation) behave as expected. The cost of a local phone call, by contrast, does not reach significance in any of the models, even in the absence of GDP per capita. ${ }^{13}$

Regressions using PCSEs confirm the significant effect of world-system status $(\mathrm{H} 1)$ and competition $(\mathrm{H} 3)$, although privatization $(\mathrm{H} 2)$ and cosmopolitanism $(\mathrm{H} 5)$ fail to reach significance. With the less restrictive generalized least squares (GLS) approach, we obtain support for each of our hypotheses, although in the case of world-system status the core dummy is not significant while the semi-periphery indicator is. Given that the significant variables tend to be so at the level of .02 or better, a Bonferroni test suggests that even if one of the three estimation methods does not produce significant results on a given variable, overall our analyses do support the hypotheses at the .04 level or better when two of the three regression models show significant results (e.g. world-system, privatization, competition, cosmopolitanism), or at the .06 level or better when only one model shows significant results (e.g. democracy).

In order to assess the possibility that our indicator of cosmopolitanism (expenditures on tourism abroad) is not appropriate because people in geographically smaller countries contiguously located to each other are more likely to travel abroad, we ran the regressions in Table 2 after adding, one at a time, a dummy for the 17 Western European countries in our sample, a dummy for the 26 Western and Eastern European countries in our sample (excluding the Ukraine and Russia), and a dummy for the above countries plus Singapore, South Korea, and Japan, given that their populations travel abroad frequently. The significant results reported in Table 2 remained significant at similar levels.

The effects of economic, regulatory, political, and sociological variables are not only statistically significant but also large in magnitude. Using the more conservative model with PCSEs, we find that a core country has on average 24 percent more Internet users than a peripheral country, while a semi-peripheral country has 40 percent more. ${ }^{14}$ Full privatization (compared to full state ownership) increases users by 11 percent, and competition in telephone services by 16 percent. A one percent increase in cosmopolitanism as measured by tourism expenditures abroad results in a .08 percent increase in Internet users, almost as large as the effect of the number of telephone lines in operation. GDP per capita exerts the largest effect together with world-system status. Thus, above and beyond the explanatory power of the control variables - which include the lagged dependent variable, GDP per capita, the number of lines in operation, call costs and the time trend - the regulatory, political and sociological variables exert significant effects. The full model using HCSEs shows results of similar magnitude. In the less restrictive GLS model, the magnitude of the effects is much larger due to the absence of the lagged dependent variable. In sum, our regression results provide relatively robust and statistically significant evidence in support for the effects of world-system, privatization, competition, democracy, and cosmopolitanism on Internet use. The effects tend to be large in magnitude.

Table 3 reports supplemental analyses with education as a control variable in addition to the others reported in Table 2. It is important to note that the sample is now about one third smaller due to missing data on literacy, the most widely available cross-national measure of education. We find approximately the same pattern of statistical support of our hypotheses in model A of Table 3. Literacy is not significant, echoing the results obtained by other researchers (e.g. Chinn and Fairlie 2004; Norris 2001:62). The reason for the lack of significance is that literacy - or any education measure, for that matter - is highly correlated with both GDP per capita (.65) and the 
number of phone lines (.63). If one excludes both variables from the equation, then literacy becomes significant regardless of the estimation method used. (See model B in Table 3.)

\section{Discussion and Conclusion}

Our results show that the growth of the Internet worldwide is driven not just by socioeconomic status, cost or accessibility but also by regulatory, political, and sociological variables, a set of findings that has eluded previous research on the global digital divide. Differences in Internet use are the result of an array of forces over which governments and multilateral organizations have varying degrees of influence. Governments can certainly implement specific policies that would make this medium more widely used by the population, namely, privatization and deregulation of the telecommunications sector, and introduction of more competition. Other key variables - like purchasing power, world-system status, democratic freedoms, and cosmopolitanism - can be affected by government policy as well, although they are part of larger and more complex policymaking arenas that transcend the telecommunications or Internet sectors. Our analysis demonstrates that, at least as far as Internet use is concerned, the variables with the largest effects in terms of magnitude are also the ones that are more complicated for any government single-handedly to shape (GDP per capita, democratic freedoms, cosmopolitanism).

One important corollary of our analysis is that if the Internet is to have profound consequences, as some have argued, they will be felt in extremely heterogeneous ways around the world. Countries differ massively in their levels of Internet use and in their exposure to the revolutionary implications of this new medium. Many of the cross-national differences in Internet use that exist today are likely to remain in place because they are the result of the fundamental economic, political and social gap that separates the advanced from the less developed countries, which to a certain degree is due to unequal power relations, as indicated by dependency and world-system status. Countries with an initial advantage in the creation, organization, and dissemination of knowledge and information seem poised to benefit disproportionately from the Internet, in yet another manifestation of the "rich-getricher," Matthew-type effect at the aggregate level. For instance, if the Internet has the potential of transforming businesses, making them more efficient and innovative, then the most advanced countries stand to benefit disproportionately from it, potentially enlarging the capability gap between firms in the advanced and the developing countries. Or if the Internet ultimately proves to enhance political participation, it will happen more intensely in countries that are already democratic. Based on the results obtained in this paper, it seems reasonable to argue that the Internet will not be the quick technological fix that will render disadvantaged countries and firms competitive, or the factor that will help spread the cause of democracy around the world. Already rich, competitive, high-status countries and firms, and already democratic countries, are likely to benefit the most from the new medium.

Our empirical analysis is limited in two main ways that future research can perhaps address. First, our reliance on publicly available information imposes constraints on the depth of the analysis. More and better international comparative data at the micro level are needed to understand the impact of political and social variables on the Internet. Also, such micro-level data will enable scholars to explore the two-way causation that may be operating between Internet use and political behavior. Second, while we used lagged effects and addressed empirically the issue of longitudinal error correlation, individual-level data and a longer time period of observation may provide the opportunity to explore endogeneity problems more carefully.

Future research can also assess how use of the Internet correlates with changes in the use of other media such as newspapers, the telephone, and television. The media industry has gone 


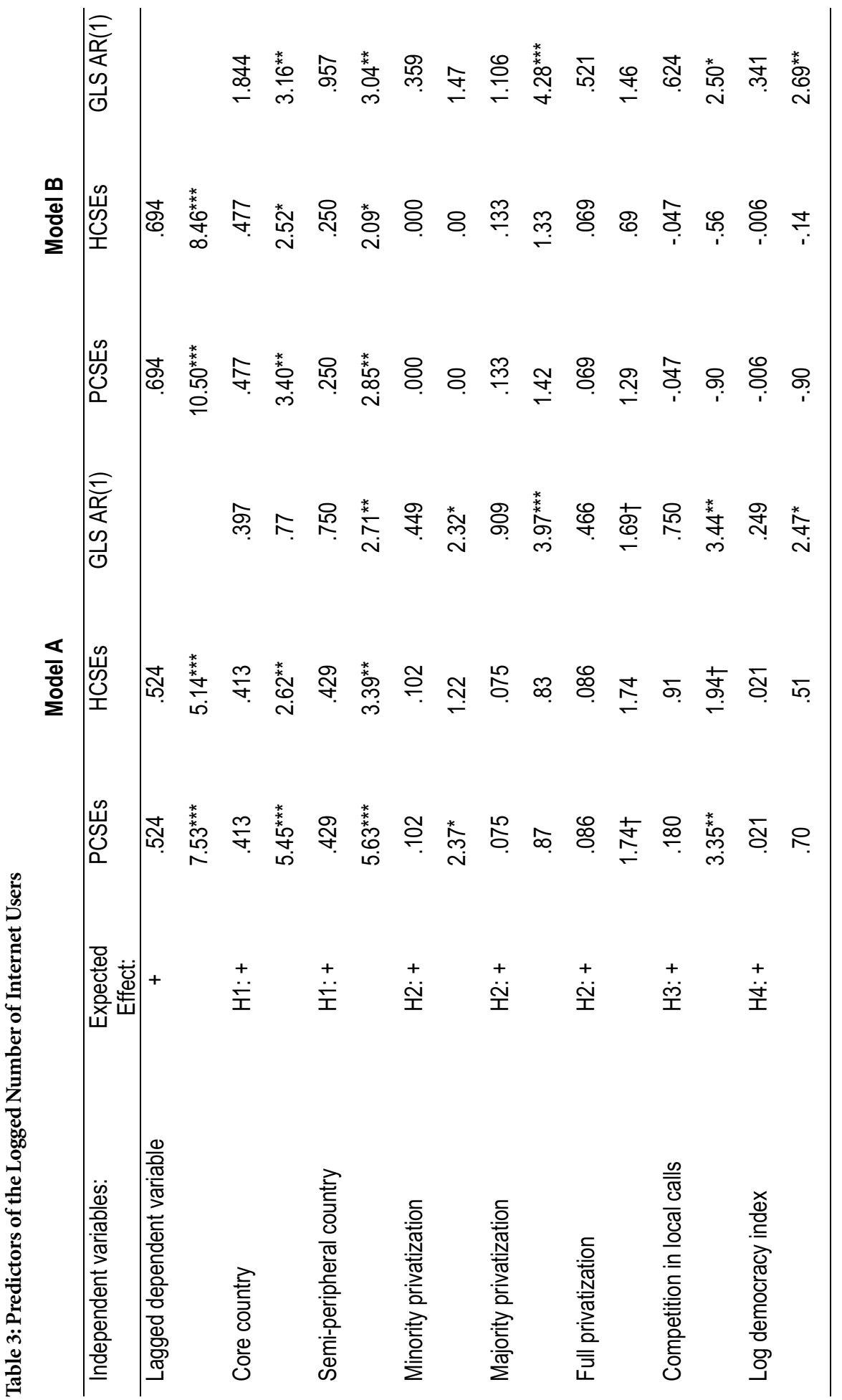


Explaining the Global Digital Divide • 699

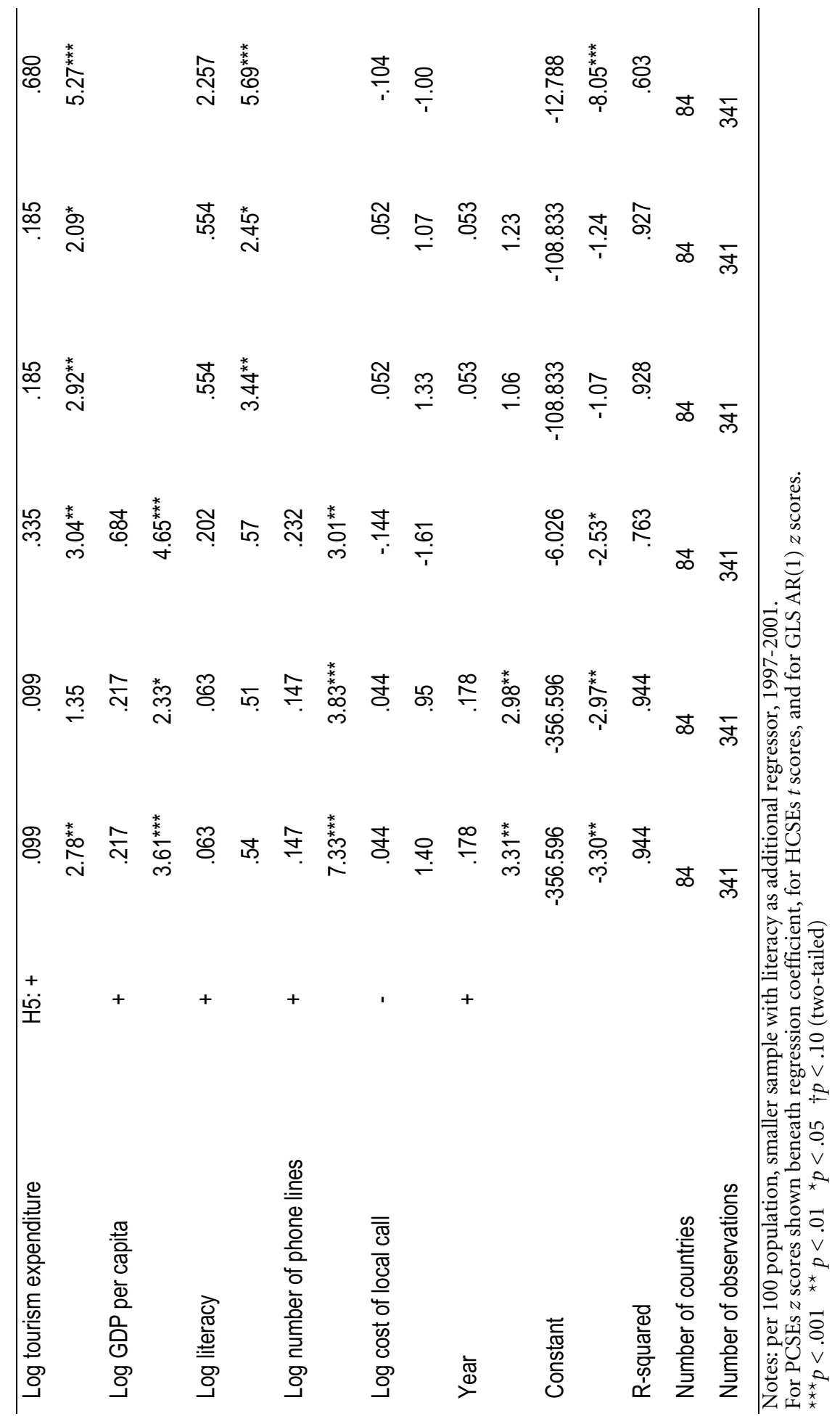


through an array of important changes over the last decade, including internationalization, consolidation, and convergence. It is not yet clear what the drivers of people's decision to use different types of media are, or what the political and social roots and consequences of such decisions might be. The development of the Internet to date confirms some of the basic theoretical arguments in the social sciences. It is a medium whose growth and diffusion are not only driven by technological and purely economic imperatives, but also by regulatory, political and sociological ones. Accordingly, its promise and potential as a truly global and globalizing medium appear to be far from realized.

\section{Notes}

1. Alternative sources of Internet use data would yield similar trends and relationships. The Pearson correlation between the time-series reported in Figure 1 and those published by NUA Internet Surveys (now part of CyberAtlas) is +.99 (NUA 2003). The ITU data are preferable because coverage starts in 1990 (as opposed to 1995 for NUA), and the quality of the information tends to be better (Abramson 2000:70; Minges 2000). Other surveys estimate use in the developed countries to be even higher. For instance, UCLA's Center for Communication Policy finds Internet users to comprise a little more than 70 percent of the U.S. population (UCLA 2003).

2. The best cross-national survey of individual-level patterns of use is the UCLA World Internet Project, which collected data in 24 developed and developing countries. Analyses of the data show the importance of economic variables (Chen, Boase and Wellman 2002).

3. A separate branch of Internet scholarship has focused on the effects of the Internet on political participation (for reviews see: Norris 2001:97-98, 112-170; Putnam 2001:169-180; Papacharissi 2002; see also: Foster and Mosco 2001; Gibson, Howard and Ward 2000; Gibson and Ward 1999; Bimber 1998, 1999, 2001; Tambini 1999).

4. Her statistical analysis based on a cross-section of Internet use by country, however, did not find a significant effect of democratic freedom (Norris 2001:62). Using a different measure of civil liberties, Beilock and Dimitrova (2003) did find a significant effect with cross-sectional data. Milner (2006) also finds a robust effect of political freedoms, using a measure similar to ours.

5. Testimony before the U.S. Congressional Human Rights Caucus, Briefing on Freedom of Expression in Vietnam, July 23, 2002 (http://www.house.gov/lantos/caucus/TestimonyNguyen Kim072302.ht). See also New York Times (November 9, 2002, p. A6), and Information Week (November 8, 2002, no page).

6. It is important to note that democracies may foster the development of the Internet because they promote economic development and the use of technology in general, and not because of they tolerate decentralized communication media to a greater extent than authoritarian or totalitarian regimes. The relationship between democracy and free markets has been observed by institutional economists and social scientists for a long time (e.g. North 1990). So as to ensure that the development of the market is not the mediating variable between democracy and Internet use, we control for the level of economic development in all of our analyses, a variable that is commonly measured as the market value of all final goods and services produced. 
7. As in the case of political participation and control, a separate part of the Internet literature has focused on the question of whether this new medium can change social behavior and relationships by enhancing the nature and frequency of social interaction, and the density of voluntary association. Some studies have found such positive effects (Gibson, Howard and Ward 2000; Boneva and Kraut 2002; Hampton and Wellman 2002; Quan-Haase and Wellman 2002; Kavanaugh and Patterson 2002), while others have concluded that the Internet tends to alienate individuals from one another and to increase social isolation (Hern and Chaulk 2000; Nie, Hillygus and Erbring 2002; Franzen 2000:435). In some cases, isolation and psychological stress were found to increase during the early stages of use (Kraut et al. 1998), but not after the user had acquired a longer online experience (Kraut et al. 2002).

8. The core includes, in order of prominence: United States, France, Germany, United Kingdom, Italy, Japan, Russia, Belgium, The Netherlands, Canada, Brazil, Spain, China, Saudi Arabia and Australia. The semi-periphery comprises Sweden, Switzerland, India, Egypt, Austria, the former Yugoslavia, Nigeria, Czechoslovakia, Iran, Argentina, Romania, Algeria, Pakistan, Mexico, Iraq, Poland, Turkey, Portugal, Libya, Greece, Indonesia and Thailand.

9. We thank Witold Henisz for providing these measures.

10. Everett (1998:387), for instance, points out that the availability of telephone lines and the cost of a call are among the most important barriers to Internet use in the developing world. Other researchers have used this variable as a proxy for Internet use costs (Kiiski and Pohjola 2002; Bauer, Berne and Maitland 2002; Oxley and Yeung 2001; Chinn and Fairlie 2004). We recognize that the cost of a local phone call is affected by fluctuations in exchange rates and in local inflation rates that may be unrelated to the cost of making a local phone call. To see if our results would change if these effects were taken into account we adjusted the cost of a local phone call in dollars by GDP per capita in dollars. The regression results were comparable in terms of signs and significance levels. We report results using the non-adjusted measure to facilitate the interpretation of the coefficient of GDP per capita.

11. Durbin's $h=-.02, t=-.45$, and $p=.65$, computed with a balanced panel of 61 countries (305 country years). Thus, the null hypothesis of zero autocorrelation cannot be rejected.

12. We implemented our statistical analyses with Stata. We used the pairwise option with the xtpcse command for PCSEs, the robust and hc3 options with the regress command for HCSEs, the xtregar command for the AR(1) model, the durbinh command for calculating Durbin's $h$, and the hadrilm command for testing for trend stationarity. The other tests and commands for stationarity available with Stata (e.g. ipshin, levinlin or madfuller) require a greater number of years than countries. We used the xtivreg command to estimate the first-difference model.

13. Finding a significant effect of cost on Internet use is common using cross-sectional data. However, only one previous study using panel data for both developed and developing countries has found a significant effect of cost on the growth of the Internet (Kiiski and Pohjola 2002), but the dependent variable was Internet computer hosts and not users. Moreover, the estimation methods they used do not correct for either serial correlation or heteroscedasticity. 
14. The magnitude of the effects of dummy variables are calculated by exponentiating the coefficient and subtracting unity. The coefficient for core tends to be smaller in magnitude than the coefficient for semi-periphery because the world-system classification by Van Rossem (1996) yields countries with a low proportion of Internet users as part of the core (e.g. Brazil, China and Saudi Arabia). These countries end up being part of the core because of their prominent role in merchandise trade (including arms) and diplomacy (Van Rossem 1996:516), although they are not as economically developed as the rest of the core.

\section{References}

Abbott, Jason P. 2001. "Democracy@internet.asia? The Challenges to the Emancipatory Potential of the Net: Lessons from China and Malaysia." Third World Quarterly 22:99-114.

Abramson, B. 2000. "Internet Globalization Indicators." Telecommunications Policy 24:69-74.

Associated Press. 2001. “Saudi Arabia Says It Will Ban 200,000 Internet Sites." AP, April 30.

Banks, Arthur S. 2001. Cross-National Time-Series Data Archive [electronic file]. www.databanks.sitehosting.net/

Bauer, Johannes M., Michel Berne and Carleen F. Maitland. 2002. "Internet Access in the European Union and in the United States." Telematics and Informatics 19:117-137.

Beck, Nathaniel. 1991. "Comparing Dynamic Specifications." Political Analysis 3:51-87.

2001. "Time-Series Cross-Section Data: What Have We Learned in the Last Few Years?" Annual Review of Political Science 4:271-293.

Beck, Ulrich. 2000. "The Cosmopolitan Perspective." British Journal of Sociology 51:79-106.

Beilock, Richard, and Daniela V. Dimitrova. 2003. "An Exploratory Model of Inter-Country Internet Diffusion." Telecommunications Policy 27:237-252.

Bimber, Bruce. 1998. "The Internet and Political Transformation: Populism, Community, and Accelerated Pluralism." Polity 31:133-160.

1999. "The Internet and Citizen Communication with Government: Does the Medium Matter?" Political Communication 16:409-428.

2001. "Information and Political Engagement in America." Political Research Quarterly 54:53-67.

Bobrow, Davis B. 1973-1974. "Mass Communication and the Political System." Public Opinion Quarterly 37:551-568.

Boneva, Bonka, and Robert Kraut. 2002. "Email, Gender, and Personal Relationships." Pp. 372-403. The Internet in Everyday Life, edited by Barry Wellman and Caroline Haythornthwaite. Blackwell.

Buchner, Bradley Jay. 1988. "Social Control and the Diffusion of Modern Telecommunications Technologies: A Cross-National Study." American Sociological Review 53:446-453.

Castells. Manuel. 2001. The Internet Galaxy. Oxford University Press.

Chen, Wenhong, Jeffrey Boase and Barry Wellman. 2002. "The Global Villagers: Comparing Internet Users and Uses around the World." Pp. 74-113. The Internet in Everyday Life. Barry Wellman and Caroline Haythornthwaite, editors. Blackwell.

Chinn, Menzie D., and Robert W. Fairlie. 2004. "The Determinants of the Global Digital Divide: A Cross- 
Country Analysis of Computer and Internet Penetration." Working Paper, Department of Economics, University of Wisconsin.

Cooper, S. David. 2000. "The Dot.Com(munist) Revolution: Will the Internet Bring Democracy to China?" UCLA Pacific Basin Law Journal 18:98-115.

Cummings, Jonathon N., Brian Butler and Robert Kraut. 2002. "The Quality of Online Social Relationships." Communications of the ACM 45(7) (July):103-108.

Davidson, Theresa, R. Sooryamoorthy and Wesley Shrum. 2002. "Kerala Connections: Will the Internet Affect Science in Developing Areas?" Pp. 496-519. The Internet in Everyday Life. Barry Wellman and Caroline Haythornthwaite, editors. Blackwell.

DiMaggio, Paul, Eszter Hargittai, W. Russell Neuman and John P. Robinson. 2001. "Social Implications of the Internet." Annual Review of Sociology 27:307-336.

Dizard, Wilson, Jr. 2000. Old Media, New Media: Mass Communications in the Information Age. Longman.

Drake, William J., Shanthi Kelathil and Taylor C. Boas. 2000. "Dictatorships in the Digital Age: Some Considerations on the Internet in China and Cuba." Working Paper, Carnegie Endowment for International Peace. www.cisp.org/imp/october_2000/10_00drake.htm

D'Souza, Juliet, and William L. Megginson. 1999a. "The Financial and Operating Performance of Privatized Firms during the 1990s." Journal of Finance, 54:1397-1438.

D'Souza, Juliet, and William L. Megginson. 1999b. "Sources of Performance Improvement in Privatized Firms: A clinical study of the global telecommunications industry." http://facultystaff.ou.edu/M/William.L.Megginson-1/

Durbin, J. 1970. "Testing for Serial Correlation in Least Squares Regression When Some of the Regressors are Lagged Dependent Variables." Econometrica 38:410-421.

Everett, Margaret. 1998. "Latin Ameica On-Line: The Internet, Development, and Democratization." Human Organization 57(4):385-393.

Fisher, Claude S. 1992. America Calling: A Social History of the Telephone to 1940. University of California Press.

Franda, Marcus. 2002. Launching into Cyberspace: Internet Development and Politics in Five World Regions. Lynne, Rienner.

Franzen, Axel. 2000. "Does the Internet Make us Lonely?" European Sociological Review 16:427-438.

Gibson, Rachel K., Philip E.N. Howard and Stephen Ward. 2000. "Social Capital, Internet Connectedness, and Political Participation: A Four-Country Study." Paper presented at the International Political Science Association, Québec, Canada.

Gibson, Rachel, and Stephen Ward. 1999. "Party Democracy On-Line: U.K. Parties and New ICTS." Information, Communication and Society 2:340-367.

Gilder, George. 2000. Telecosm: How Infinite Bandwidth will Revolutionize the World. Free Press.

Granovetter, Mark. 1973. "The Strength of Weak Ties." American Journal of Sociology 78:1360-1380.

Guillén, Mauro F., and Sandra L. Suárez. 2001. "Developing the Internet: Entrepreneurship and Public Policy in Ireland, Singapore, Argentina, and Spain." Telecommunications Policy 25:349-371.

Gunaratne, Shelton A. 2002. "An Evolving Triadic World: A Theoretical Framework for Global Communication Research." Journal of World-Systems Research 8(3):329-365. 
Habermas, Jurgen. 1989. The Structural Transformation of the Public Sphere. The MIT Press.

Hadri, Kaddour. 2000. "Testing for Stationarity in Heterogeneous Panel Data." The Econometrics Journal 3:148-161.

Hampton, Keith N., and Barry Wellman. 2002. "The Not So Global Village of Netville." Pp. 345-371. The Internet in Everyday Life. Barry Wellman and Caroline Haythornthwaite, editors. Blackwell.

Hancock, Bill. 1999. "Internet Users Furious over SingTel's Computer Security Probe." Computers and Security 18(4):288-289.

Hargittai, Eszter. 1999. "Weaving the Western Web: Explaining differences in Internet connectivity among OECD countries." Telecommunications Policy 23:701-718.

Havick, John. 2000. "The Impact of the Internet on a Television-Based Society." Technology in Society 22:273-287.

Haythornthwaite, Caroline, and Barry Wellman. 2002. "The Internet in Everyday Life." Pp. 3-41 in The Internet in Everyday Life. Barry Wellman and Caroline Haythornthwaite, editors. Blackwell.

Henisz, Witold J. 2000. "The Institutional Environment for Economic Growth." Economics and Politics 12:131.

Henisz, Witold J., and Bennet A. Zelner. 2001. "The Institutional Environment for Telecommunications Investment." Journal of Economics \& Management Strategy 10:123-148.

Henisz, Witold J., Bennet A. Zelner, and Mauro F. Guillén. 2005. "The Worldwide Diffusion of Market-Oriented Infrastructure Reform, 1977-1999." American Sociological Review, forthcoming.

Herman, Edward S., and Noam Chomsky. 2002. Manufacturing Consent. Pantheon Books.

Hern, Matt, and Stu Chaulk. 2000. "Roadgrading Community Culture: Why the Internet is so Dangerous to Real Democracy." Democracy \& Nature 6(1):111-120.

Hogan, Sarah B. 1999. "To Net or not to Net: Singapore's Regulation of the Internet." Federal Communications Law Journal 51(2):429-446.

Holloway, Grant. 2002. "China Blocking 10 Percent of Internet." CNN.com, December 3. edition.cnn.com/2002/world/asiapcf/east/12/03/china.internet/

Horrigan, John B. 2003. "Adoption of Broadband to the Home." Pew Internet and American Life Project: www.pewinternet.org

Iran. 2003. "Hardliners Step Up Control of Internet." Reporters sans frontiers - Iran, January 6, 2003. www.rsf.org/article.php3?id_article $=4699$

ITU (International Telecommunication Union). 2000. "Telecommunications at a Glance." www.itu.int/ti/

2002. World Telecommunication Development Report. Geneva: International Telecommunication Union.

2003. World Telecommunications Indicators: Database. http://www.itu.int/ti/publications/ world/world.htm.

Jones, Steven. 2000. "The Bias of the Web." Pp. 171-182 in The World Wide Web and Contemporary Cultural Theory: Magic, Metaphor and Power. Andrew Herman, editor. Routledge.

Katz, James E., Ronald E. Rice and Philip Aspden. 2001. "The Internet, 1995-2000." American Behavioral Scientist 45:405-419. 
Kavanaugh, Andrea L., and Scott J. Patterson. 2002. "The Impact of Community Computer Networks on Social Capital and Community Involvement in Blacksburg." Pp. 325-344. The Internet in Everyday Life. Barry Wellman and Caroline Haythornthwaite, editors. Blackwell.

Kirkman, Geoffrey S., Peter K. Cornelius, Jeffrey D. Sachs and Klaus Schwab. eds. 2002. Global Information Technology Report 2001-2002. Oxford University Press.

Kiiski, Sampsa, and Matti Pohjola. 2002. "Cross-Country Diffusion of the Internet." Information Economics and Policy 14:297-310.

Kraut, Robert, Sara Kiesler, Bonka Boneva, Jonathon Cummings, Vicki Helgeson and Anne Crawford. 2002. "Internet Paradox Revisited." Journal of Social Issues 58:49-74.

Kraut, Robert, Michael Patterson, Vicki Lundmark, Sara Kiesler, Tridas Mukopadhyay and William Scherlis. 1998. "Internet Paradox: A Social Technology that Reduces Social Involvement and Psychological Well-Being?" American Psychologist 53:1017-1031.

Leduc, Patrick. 2000. "Burma Wards Off the Internet Revolution." Digital Freedom Network, January 31, 2000. dfn.org/news/burma/web-crackdown.htm

Legard, David. 1999. "Malaysia Scraps Cyber Curbs, Report Says." Computer World Hong Kong, March 19 www.cw.com.hk/Analysis/a990319001.htm

Levy, Brian, and Pablo T. Spiller. 1994. "The Institutional Foundations of Regulatory Commitment: A Comparative Analysis of Telecommunications Regulation." Journal of Law, Economics and Organization, 10:201-246.

Lindblom, Charles. 1977. Politics and Markets. Basic Books.

Long, J. Scott, and Laurie H. Ervin. 2000. "Using Heteroscedasticity Consistent Standard Errors in the Linear Regression Model." American Statistician 54:217-224.

Lorimer, Rowland. 2002. "Mass Communication: Some Redefinitional Notes." Canadian Journal of Communication 27:63-72.

McChesney, Robert W. 1999. Rich Media, Poor Democracy. University of Illinois Press.

2000. "So Much for the Magic of Technology and Free Market: The World Wide Web and the Corporate Media System." Pp. 5-37. The World Wide Web and Contemporary Cultural Theory: Magic, Metaphor and Power. Andrew Herman, editor. Routledge.

McDaniel, Drew. 2002. Electronic Tigers of Southeast Asia: The Politics of Media, Technology, and National Development. lowa State University Press.

Maitland, Carleen F., and Johannes M. Bauer. 2001. "National Level Culture and Global Diffusion: The Case of the Internet." Pp. 87-128. Culture, Technology, Communication: Towards an Intercultural Global Village. Charles Ess, editor. State University of New York Press.

Marshall, Monty G., and Keith Jaggers. 2002. "Polity IV Project: Political Regime Characteristics and Transitions, 1800-1999. Dataset Users' Manual." College Park, MD: Center for International Development and Conflict Management. Available at: http://www.cidcm.umd.edu/inscr/polity/p4manual.pdf

Megginson, William L., and Jeffry M. Netter. 2001. "From State to Market: A survey of empirical studies on privatization." Journal of Economic Perspectives 34:321-389.

Merton, Robert K. [1957] 1968. "Patterns of Influence: Local and Cosmopolitan Influentials." Pp. 441-474 in Social Theory and Social Structure. Free Press. 
Michels, Robert. [1911] 1962. Political Parties: A Sociological Study of the Oligarchical Tendencies of Modern Democracy. Free Press.

Milner, Helen. 2006. “The Digital Divide: The Role of Domestic Political Institutions in the Spread of the Internet." Comparative Political Studies, forthcoming.

Minges, Michael. 2000. "Counting the Net: Internet Access Indicators." Geneva: ITU. http://www.isoc.org/ isoc/conferences/inet/00/cdproceedings/8e/8e 1.htm

Mosaic Group. 1998. The Global Diffusion of the Internet Project: An Initial Inductive Study. www.agsd.com/gdi97/gdi97.html

Mosco, Vincent. 1996. The Political Economy of Communication. Sage.

2000. "Public Policy and the Information Highway - Access, Equality and Universality - Report to the National Library of Canada." http://qsilver.queensu.ca/sociology/vmpubpol.htm

Mosco, Vincent, and Derek Foster. 2001. "Cyberspace and the End of Politics." Journal of Communication Inquiry 25(3):218-236.

Negroponte, Nicholas. 1995. Being Digital. Knopf.

Nie, Norman H., D. Sunshine Hillygus and Lutz Erbring. 2002. "Internet Use, Interpersonal Relations, and Sociability." Pp. 215-243. The Internet in Everyday Life. Barry Wellman and Caroline Haythornthwaite, editors. Blackwell.

Norris, Pippa. 2001. Digital Divide: Civic Engagement, Information Poverty, and the Internet Worldwide. Cambridge University Press.

North, Douglass C. 1990. Institutions, Institutional Change, and Economic Performance. Cambridge University Press.

NUA. 2003. "How Many Online?" http://www.nua.ie/surveys/how_many_online/index.html

O'Sullivan, Tim, J. Hartley, D. Saunders and J. Fiske. 1983. Key Concepts in Communication. Methuen.

Oxley, Joanne E., and Bernard Yeung. 2001. "E-commerce Readiness: Institutional Environment and International Competitiveness." Journal of International Business Studies 32:705-723.

Papacharissi, Zizi. 2002. “The Virtual Sphere: The Internet as a Public Sphere." New Media \& Society 4:9-27.

Petrazzini, Ben A., and Theodore H. Clark. 1996. "Costs and Benefits of Telecommunications Liberalization in Developing Countries." Working Paper, Hong Kong University of Science \& Technology.

Putnam, Robert D. [2000] 2001. Bowling Alone: The Collapse and Revival of American Community. Simon \& Schuster.

Press, Larry, Grey Burkhart, Will Foster, Sy Goodman, Peter Wolcott and Jon Woodard. 1998. "An Intenet Diffusion Framework." Communications of the ACM 41:21-26.

Pritchett, Lant. 1997. “Divergence, Big Time." Journal of Economic Perspectives 11(3):3-17.

Quan-Haase, Anabel, and Barry Wellman. 2002. "Capitalizing on the Net: Social Contact, Civic Engagement, and Sense of Community." Pp. 291-324. The Internet in Everyday Life. Barry Wellman and Caroline Haythornthwaite, editors. Blackwell.

Radio Free Europe. 1999. "The 20 Enemies of the Internet." www.rferl.org/nca/special/enemies.html

Ragin, Charles, and Daniel Chirot. 1984. "The World System of Immanuel Wallerstein: Sociology and Politics and History." Pp. 276-312. Vision and Method in Historical Sociology. Theda Skocpol, editor. Cambridge University Press. 
Robinson, John, and Alan Neustadtl. 2002. "Social Contact Differences Between Internet Users and Nonusers in the General Social Survey." IT \& Society (1)1:73-102.

Robinson, John P., Meyer Kestnbaum, Alan Neustadtl and Anthony Alvarez. 2002. "The Internet and Other Uses of Time." Pp. 244-262. The Internet in Everyday Life. Barry Wellman and Caroline Haythornthwaite, editors. Blackwell.

Rodan, Garry. 1996. "Information Technology and Political Control in Singapore." Working Paper \#26, Japan Policy Research Institute www.jpri.org/jpri/wp26.html

. 1998. "The Internet and Political Control in Singapore." Political Science Quarterly 113:63-89.

Rogers, Everett M. 1995. Diffusion of Innovations. Free Press.

. 2001. "The Digital Divide." Convergence 7(4):96-111.

RSF (Reporters san frontières). 1999. "The 20 Enemies of the Internet." Radio Free Europe/Radio Liberty www.rferl.org/nca/special/enemies/html

Samoriski, Jan H. 2000. "Private Spaces and Public Interests: Internet Navigation, Commercialism and the Fleecing of Democracy." Communication Law and Policy 5:93-113.

Scannell, Paddy. 1996. Radio, Television, and Modern Life. Blackwell.

Schiller, Herbert. 1996. Information Inequality: The Deepening Social Crisis in America. Routledge.

Schneider, Steven M. 1996. "Creating a Democratic Public Sphere through Political Discussion." Social Science Computer Review 14:373-393.

Smith, Dave A., and Douglas R. White. 1992. "Structure and Dynamics of the Global Economy: Network Analysis of International Trade, 1965-1980." Social Forces 70:857-893.

Sohmen, Philip. 2001. "Taming the Dragon: China's Efforts to Regulate the Internet." Stanford Journal of East Asian Affairs 1:17-26.

Star, Shirley, and Helen M. Hughes. 1950. "Report of an Educational Campaign: the Cincinnati Plan for the United Nations." American Journal of Sociology 55:389-397.

Sussman, Leonard R. 2000. "Censor Dot Gov: The Internet and Press Freedom 2000." Freedom House Press Freedom Survey 2000. www.freedomhouse.org/pfs2000/sussman.html

Szerszynski, Bronislaw, and John Urry. 2002. "Cultures of Cosmopolitanism." Sociological Review 50:461-481.

Tambini, Damian. 1999. "New Media and Democracy : The Civic Networking Movement." New Media \& Society 1:305-329.

Tapscott, Don, and Art Caston. 1993. Paradigm Shift: The New Promise of Information Technology. McGraw-Hill.

Taubman, Geoffry. 1998. "A Not-So World Wide Web ? The Internet, China, and the Challenges of Nondemocratic Rule." Political Communication 15:255-272.

Tichenor, P. J., G. A. Donohue, and C. N. Olien. 1970. "Mass Media Flow and Differential Growth of Knowledge." Public Opinion Quarterly 34:159-170.

UCLA. 2000. Surveying the Digital Future. Los Angeles, CA: UCLA Center for Communication Policy.

2003. Surveying the Digital Future: Year Three. Los Angeles: UCLA Center for Communication Policy. www.ccp.ucla.edu 
U.S. Department of Commerce. 1999. Falling through the Net: Defining the Digital Divide. Washington, DC: U.S. Department of Commerce.

Van Dyjk, Jan. 1999. The Network Society: Social Aspects of New Media. Sage.

Van Rossem, Ronald. 1996. "The world-system paradigm as general theory of development: A crossnational test." American Sociological Review 61:508-527.

Viswanath, K., and John R. Finnegan, Jr. 1996. "The Knowledge Gap Hypothesis: Twenty-Five Years Later." Pp. 187-227. Communication Yearbook 19. Brent Burelson, editor. Sage.

Volken, Thomas. 2002. "Elements of Trust: The Cultural Dimension of Internet Diffusion Revisited." Electronic Journal of Sociology 6(4).

Wasko, Janet. 2001. Understanding Disney: The Manufacture of Fantasy. Polity Press.

Wallerstein, Immanuel. 1974. The Modern World System. Academic Press.

Wallsten, Scott J. 2001. "An Econometric Analysis of Telecom Competition, Privatization, and Regulation in Africa and Latin America." Journal of Industrial Economics 49:1-19.

Wellman, Barry. 2001. "Computer Networks and Social Networks." Science 293:2031-2034.

Wellman, Barry, Anabel Quan Haase, James Witte and Keith Hampton. 2001. "Does the Internet Increase, Decrease, or Supplement Social Capital?" American Behavioral Scientist 45:436-455.

Wilson, Ernets J., III. 1998. "Inventing the Global Information Future." Futures 30:23-42.

World Bank. 2003. World Development Indicators 2002. CD-ROM database. Washington, D.C.: The World Bank.

2004. Ed Stats. http://www1.worldbank.org/education/edstats/. Washington, D. C.: The World Bank.

Wynn, Eleanor, and James E. Katz. 1997. "Hyperbole over Cyberspace: Self-Presentation and Social Boundaries in Internet Home Pages and Discourse." The Information Society 13:297-327.

Yamamoto, Mike. 1996. "Vietnam Issues Internet Restrictions." CNET News.com, June 4. news.com.com/2100-1023-213703.html?legacy=cnet

Zittrain, Jonathan, and Benjamin Edelman. 2002. "Documentation of Internet Filtering in Saudi Arabia." Working Paper, Berkman Center for Internet \& Society, Harvard Law School. Cyber.law.harvard.edu/filtering/saudiarabia/

2003. "Empirical Analysis of Internet Filtering in China." Working Paper, Berkman Center for Internet \& Society, Harvard Law School. Cyber.law.harvard.edu/filtering/china/ 